\title{
CONSUMER PERCEPTION OF QUALITY OF CLOTHING PRODUCTS: A LESSON FOR THE BUSINESS SECTOR ARISING FROM CZECH EVIDENCE
}

\author{
Hinčica, V., Svobodová, A., Řezanková, H.
}

Vit Hinčica / Prague University of Economics and Business, Faculty of International Relations, Department of International Business, Winston Churchill Sq. 1938/4, 130 67, Prague, Czech Republic. Email:xhinv02@vse.cz

Anna Svobodová / Prague University of Economics and Business, Faculty of International Relations, Department of International Business, Winston Churchill Sq. 1938/4, 130 67, Prague, Czech Republic. Email: svoa02@vse.cz

Hana Řezanková / Prague University of Economics and Business, Faculty of Informatics and Statistics, Department of Statistics and Probability, Winston Churchill Sq. 1938/4, 130 67, Prague, Czech Republic. Email: hana.rezankova@vse.cz

\begin{abstract}
The paper assesses the perception of clothing products' quality using two independent samples of Czech respondents answering a questionnaire. It fills the current research gap in revealing how the quality of clothing products is currently perceived by different sociodemographic groups and whether other factors neglected previously (e.g., type of store, store's trade name, etc.) contribute to the perceived garment quality. The results show that age plays an important role in assessing some of the parameters by which people define whether garments are quality garments. This demographic criterion also influences the intensity of quality consideration when people buy a product, but no statistically significant dependence was found for the intensity of quality consideration when people buy a clothing product. These and other papers' results may help companies in the clothing industry, and the related sectors better comprehend how different categories of people determine garment quality.

Implications for Central European audience: Businesses active in the apparel and fashion industries may better understand the current preferences of Czech customers regarding their clothing quality perceptions. The results could also be useful for managers in other countries of the Central-European region.
\end{abstract}

Keywords: quality perception; clothing industry; consumers; businesses; Czech Republic JEL Classification: L15, M11, M31, D9, L21

\section{Introduction}

In the past decades, product quality has become an increasingly important issue for consumers, companies, and also for scientists. The possible definitions of the term "quality" 
have been extensively provided by several authors (Mitra, 2016), and it can be said that the theory on the understanding of quality is well covered. However, under any definition, it is possible to agree with Miller (1992) or other authors coming after (Tyagi et al., 2015), who stressed that "quality is defined by the customer." Although the customer matters in this sense, there is still a significant knowledge gap about how customers perceive the quality of different products and services in different parts of the world.

One of the industrial sectors broadly dealing with all the levels of quality is the clothing industry. Analogically to the statement above, little is known about the perceived quality of this industry's products. Moreover, the question of how the different main socio-demographic groups of consumers perceive clothing quality is also being insufficiently answered. This paper focuses on these topics on the basis of the respondents' answers in the Czech Republic. In this country, no specific research on garment quality perception has been launched so far.

The aim of the paper is to determine the level of importance of several factors by which consumers in the Czech Republic perceive the quality of garments. First, the factors customers consider more important or less important when evaluating the quality of clothing will be studied. Second, the questions of whether customers' opinions relating to quality evaluation and the purchase of clothing depend on gender, age, education, and permanent place of living will be analyzed. Two questionnaire surveys were conducted to answer the questions. The data obtained from the two surveys are first analyzed separately for each data set, and then the results of the analyzes are compared on the basis of these two surveys. Descriptive statistics and various statistical tests on the independence of variables are used. Cluster analysis will be applied to illustrate the relationships between factors that customers might consider important in assessing quality.

The identified relationships can serve as a theoretical basis for conducting surveys in other countries or for investigations into product types other than clothing. The output should primarily inform managers in the clothing industry and related businesses in the Czech Republic about how quality is currently perceived and associated with places where garments are offered. The results could also be useful for managers in other countries of the CentralEuropean region.

\section{Literature review}

In this section, we first make clear which terms will be used in the paper. Then, selected publications focused on the perceived quality in the clothing industry are commented. Scientific hypotheses for our research will also be formulated.

\subsection{Definition of the clothing industry}

The clothing industry encompasses all activities related to the design, production, and sale of clothing products (Lane \& Probert, 2004). Despite influencing a human's everyday life, it appears very challenging to find figures to demonstrate the real importance of the clothing industry in world economics. Two primary reasons can explain this difficulty.

First, two other terms are often used instead of "clothing industry", and these terms are "apparel industry" and "fashion industry". However, these terms might not always be understood as those that cover any clothing product (see, e.g., Steele \& Major, 2015). So, 
the respective statistics for the apparel/fashion industries may not comprehend all clothing products, and they also may not comprehend some of the activities expressed at the beginning of this subsection. Second, statistics tend to be collected for the textile and clothing industries together because the textile and clothing industries are often seen together or even as one industry due to their interdependence (Stengg, 2001; Yürek et al., 2019). Besides, another term can be used as a substitute for the "clothing industry", which is the "garment industry". Therefore, one has to be very careful when applying any of the terms stated herein.

This paper will use the terms "clothing industry" and "garment industry" interchangeably as our research's preferred terms due to the above-stated arguments. Likewise, "clothes," "clothing product," and "garment" will be used as synonyms. We will refrain from using the words "fashion" and "apparel" to avoid any possible misinterpretation.

Although this paper considers the clothing industry independently of the textile industry, a look at the statistics tracked for both industries together is worth taking because it indicates that the clothing industry can contribute to some countries' GDP by up to several per cent (see, e.g., Milašius \& Mikučioniené, 2014, World Bank, 2020). This fact sufficiently evidences the industry's importance. Moreover, the clothing industry influences many other sectors, apart from the textile industry.

Authors of several studies conducted to date on topics associated with garment perceived quality have often admitted that their findings could not be generalized for more countries as it was the case of, e.g., Rahman's et al. study (2017) of apparel Chinese and Canadian consumer preferences and the role of product-evaluative cues, or Erdoğmuş and BüdeyriTuran's paper (2012) on the role of personality congruence, perceived quality and prestige on ready-to-wear brand loyalty. Other authors, in turn, could not make generalizations for the socio-demographic groups they analyzed (e.g., Salerno-Kochan \& Turek, 2021, or some of the other authors cited further below). Therefore, trying to learn more about how people consider garment quality in this sector and in other countries is worth investigating.

\subsection{Perceived quality in the clothing industry}

Product perceived quality directly influences the purchase intention (Saleem et al., 2015), and it appears to be one of the most important constructs in marketing (Tsiotsou, 2005). Nonetheless, other segments of a product's value chain can benefit from this knowledge, especially those connected to planning and production. Businesses in the clothing industry need to improve sales forecast accuracy (Thomassey, 2010), so providing them with additional information on people's behaviour may benefit them.

Several authors have already dedicated attention to the topic of perception of clothing quality. Swinker and Hines (2006) summarized earlier research and also surveyed students that were requested to evaluate clothing quality. The goal was to determine the types of informational cues (grouped into intrinsic, extrinsic, appearance, and performance categories) used by consumers when evaluating clothing quality and their expectations of a high-quality garment. The authors' findings supported previous research suggesting that consumers' perception of clothing quality is multidimensional. A similar statement has been recently provided by Aakko and Niinimäki (2021) in their theory-only paper, which reviewed the current literature on the perceived quality of clothing to look for connections between quality and clothing use time. 
It is imperative to say that since 2006, few studies on perceived garment quality followed till nowadays, and these studies usually worked with a narrowly determined profile of respondents (e.g., older women in the studies of Du Preez et al., 2018; Coelho, 2016; or students in the study of Pujara \& Chaurasia, 2010; college students in the study of Gitimu et al., 2013; or female students in the study of Salerno-Kochan \& Turek, 2021) or were also dealing with particular types of clothing products (e.g., a study of Park, 2015, who surveyed college students to determine criteria for evaluating the quality of organic clothes). These studies, apart from other non-common results, also tended to support the idea that quality is a multidimensional concept. Due to the fact that some of the afore-cited authors tended to group the different cues (factors, parameters) they used, we formulate the first hypothesis for our research aiming at the Czech Republic:

\section{H1: It is possible to identify groups of factors that customers might consider important in assessing quality.}

Demographic factors may have an effect on assessing quality (Aakko \& Niinimäki, 2021). However, even the typical ones have not been sufficiently studied yet. For the sake of illustration, Salerno-Kochan and Turek (2021), at the end of their study on consumer assessment of the quality of clothing using sensory analysis, recommended that in order to get a better description of consumer quality assessment, other consumer groups, including gender, age groups or country of origin, should be investigated. Following this recommendation, this research will work with four basic socio-demographic factors - apart from the recommended age and sex, and it will also include the level of education and permanent place of living.

Out of the four socio-demographic variables, gender has so far been the most linked to the issue of the perception of garment quality. A study worth mentioning conducted by Freire Castelo and de Oliveira Cabral (2018) on the perception of clothing quality per gender was performed in 2016 with a sample of 295 consumers from the Brazilian city of Fortaleza. A notable finding from the study states that women have a higher perception than men regarding evaluating the quality attributes of both women's wear and menswear. A similar result was achieved by Gitimu et al. (2013), who, with the use of a 309-college student sample in the US, learned that women and men did differ in the evaluation of garment quality with women using more cues to evaluate garment quality than men. Additionally, in a study conducted by Lee and Workman (2021), a sample of 138 male and 131 female US university members were questioned to examine differences in time-of-adoption groups (trendsetters, early adopters, late adopters, reluctant adopters) and gender regarding brand loyalty, perceived quality, and word-of-mouth (WOM). They found that women and men evaluated clothing quality differently. The different perception of clothing quality between genders has been found out in other studies, too (Rahman et al., 2017). Therefore, for our research, we formulate:

\section{H2: Some meritorious variables depend on gender.}

Popa and Pelau (2016) investigated differences in the clothing brand perception depending on generation. They concluded that there is a difference between generations once a brand is taken into consideration when determining that a clothing product is of quality. This is the only recent study trying to assess the possible link between age and perceived garment quality. Suppose that: 
H3: Some meritorious variables depend on age.

The level of education is often used as a socio-demographic variable in scientific surveys. Nonetheless, it was impossible to find a study connecting this variable with the issue of the perception of clothing quality. According to Salerno-Kochan and Turek (2021), educated consumers are more aware of the role of quality-deciding factors, and therefore assign greater value to inherent properties. Therefore, suppose that the level of education may play some role in how clothing quality may be perceived:

\section{H4: Some meritorious variables depend on education.}

Permanent residence is another frequently used socio-demographic factor in scientific surveys. Yet, no research has associated the perception of clothing quality with this variable, and it was even impossible to find any recent statement on how consumers may behave depending on this parameter. Given the way how we formulated $\mathrm{H} 2$ to $\mathrm{H} 4$, also suppose that:

\section{H5: Some meritorious variables depend on a permanent place of living.}

It should also be noted that when investigating the issue of quality perception of garments, investigators rarely went beyond examining attributes or cues related to clothing products. An example of a cross-topic approach can be seen in Connor-Crabb and Rigby's paper (2019) where clothing production's sustainability was slightly discussed.

Although it might not be obvious from the previous lines, it should also be pointed out that the past research on quality perception topics within the clothing industry has been primarily aiming to add pieces to the theory base rather than provide implications and recommendations for the business sphere. On the other hand, there has been a growing interest among scholars for quality-related management in the garment industry, as evidenced by different papers (Chowdhury et al., 2007). However, this tendency does not change the fact that recent primary data giving insight into consumers' quality perception are still scarce. Thus, companies from the garment industry and other associated industries (textile, fashion, retail, etc.) cannot get a more complex idea of what measures they could introduce to better satisfy customer needs.

\section{Research design and methodology}

To assess the perception of quality as described above and adequately fill some of the existing gaps in past research, we drafted a questionnaire. It consists of 11 questions; seven of them focus on the studied topic, and four of them are analytical to obtain sociodemographic data. Below, the seven meritorious questions are presented first.

At the beginning of the survey, people were not informed about the survey's exact contents; they only knew that the questionnaire would be on quality perception. In the first question, we inquire about the frequency with which people focus on quality when buying any product (the question is abbreviated as "product quality"). The second question, which was not to be displayed simultaneously as the first one, is similar, but it also mentions a clothing product (also referred to as "clothing product quality"). Both questions offered five answer options. People consider quality unevenly for different product categories, so the first question has come with the risk of being too vague to get accurate replies. On the other hand, this approach of going from a general inquiry to a more specific one enables us to achieve two findings. First, it is possible to learn if people have a tendency to reply in the same way when asked 
about a clothing product after having to say how they generally act when buying any product. Second, it is possible to learn if a respondent paid enough attention to the questionnaire to eliminate unreliable answers (e.g., answering "never" in the first question and "always" in the second question).

The third question offers eleven various parameters. People were asked to indicate on a fivepoint Likert scale the importance they assign to every parameter to consider a garment as of quality. The list with the parameters was taken from another questionnaire on quality perception prepared by the Association of Small and Medium-Sized Enterprises and Crafts of the Czech Republic (see https://amsp.cz/about-us/?lang=en). As this questionnaire was suitable for any product, it was freed from parameters inconvenient for our survey (e.g., "perishable"), while other parameters were only slightly modified linguistically.

After reading other research works that discussed associations between different factors and quality - apart from the afore-mentioned sources, we can cite Davis (1987), Kaplan and Okur (2008), Kaynak et al. (2000), Lee et al. (2009) -, we considered that the chosen parameters formulated in question 3 for determining a clothing product's quality are relevant and concise. As question 3's structure also remained unquestioned during the pilot survey (see below), there was no need to change it. The eleven parameters are long service life (abbreviated furthermore also as "service life"); quality material (abb. "material"); corresponding price (abb. "price"); meeting functional expectations (abb. "functionality"); design, appearance, attractive packaging (abb. "appearance"); quality of processing (abb. "processing"); composition corresponding to the declared (abb. "composition"); good reputation, recommendations, reviews, own experience (abb. "reputation"); region of production (e.g. a Czech product, not an Asian one) (abb. "region"); brand (abb. "brand"); harmlessness to health (abb. "harmlessness").

In the fourth question, we wanted to learn to what extent people agree with the statement that higher clothing prices indicate higher quality (with answers on a four-point scale), and by the fifth question, we investigated whether people are willing to pay extra for higher-quality clothing (with answers "yes" and "no"). The introduction of questions 4 and 5 regarding the relationship between quality and price was also motivated by past research. Price belongs to the most commonly used signals of perceived product quality (Jacobson \& Aaker, 1987) and has almost always been mentioned whenever perceived garment quality was analyzed. For the formulation of question 4, we were directly inspired by the title of Gerstner's (1985) article. Regarding question 5, we found out that people's willingness to pay more for a higher-quality product is also a common research subject - currently interesting due to sustainability concerns, as evidenced by, e.g., Jung and Jin's (2014) paper on slow fashion and Bhardwaj and Fairhurst's (2010) paper on fast fashion.

We also formulated two questions ( 6 and 7 ) regarding associations people create between a place of shopping and garment quality. In question 6, we wanted to learn whether people agree with the statement that the type of store is an indicator that more quality goods appear in it than low-quality goods (e.g., a fashion boutique vs an Asian store). In question 7, we asked people whether they agree with the statement that the store's trade name is an indicator that more quality goods than low-quality goods will appear in it (e.g., a Zara store vs a store with an unknown name). Both questions were with answers on a four-point scale. Questions 6 and 7 inquiring about stores offering garments represent an attempt to support 
the idea that there is, as reported by several studies, a significant impact of where a product is bought on consumer perception of product quality (D'Astous \& Saint-Louis, 2005).

Questions 8 to 11 focused on the inquired socio-demographic indicators, and the following categories were covered by the questions: two categories for respondent's sex, six age intervals, three categories for the completed level of education (primary, secondary, university), and 14 Czech regions for a permanent place of living. As it will be mentioned further, some categories were represented by a low number of respondents, therefore for the purpose of statistical analyses, the indicators "age" and "permanent place of living" were recoded into a smaller number of categories. In the case of age, we used intervals " 25 years and less" and "26 years and more", and in the case of place of living, we used categories "Prague and the Central Bohemian region" and "other regions".

The questionnaire was prepared in the second half of August and tested with a pilot sample of 10 people to find possible imperfections. When these were adjusted, we decided to start the survey on 3rd September 2020. As it was impossible to carry out a random sampling of the whole Czech population, we opted for two sampling methods: convenience sampling and volunteer sampling. Thus, we were able to get our questionnaire to two independent samples of people. In the first case, we managed to contact around 450 people by social networks Facebook and MS Teams (the exact number of addressed people could not be counted as someone else could also be contacted by people contacted by us).

In the second case, we used the website "vyplnto.cz" where people can post their questionnaires, either for free or against a fee, to get premium services. The questionnaire was launched on 3rd September and lasted till 21st September. We did not send the link to any person, so we only waited for answers from people visiting the website. The website did not allow us to generate a four-point scale. Therefore, we included the option "I do not know". Then, in the analysis process, we eliminated all the "I do not know" replies, which means that fewer answers were eligible for some questions, namely 4,6 , and 7.

For the investigation of relationships between parameters included in question 3 (in pairs), we use the correlation coefficient. All relationships together are presented in the dendrogram as the result of cluster analysis employing the complete linkage method based on the correlation coefficient as the similarity measure. For investigated relationships between target variables based on questions 1 to 7 (six ordinal variables and one dichotomous variable), and the socio-demographic (explanatory) indicators obtained from questions 8 to 11 (categorical variables), we applied the nonparametric tests.

For the reason of low frequencies of some categories in explanatory variables, variables age and permanent place of living were recoded into variables with two categories ("25 years and less" and "26 years and more" for age and "Prague and the Central Bohemian region" and "other regions" for a place of living). For explanatory variables with two categories, the MannWhitney test was applied. For the explanatory variable with three categories (completed level of education), the Kruskal-Wallis test was used. In addition, the Pearson chi-square test of independence in a contingency table was applied for all investigated relationships. For question 5 (with answers "yes" and "no"), the chi-square test was only used. To express the intensity of dependence, Cramer's $V$ (with the values for 0 to 1 ) was applied. 


\section{Results}

Herein, we first treat our samples independently, starting with the convenience sample, and after that, we compare results obtained by statistical analyses of the two samples. Moreover, we test whether respondents' answers depend on the type of sample. Finally, we state whether it is possible to confirm the formulated hypotheses.

\subsection{Convenience sample}

From convenience sampling, we received 246 answers (105 men and 141 women) from the whole Czech Republic within a few days, mostly from the Central Bohemian region. This represents a return rate of $54 \%$. Looking at the data set we downloaded, we have not detected any suspicious way of answering (compare answers to the two first questions). Therefore, no reply has been excluded.

All people replied they consider quality to some extent when buying a product, and only one person stated never considering the quality of a clothing product when buying it (see Table 1). The convenience sample results also reveal that $87 \%(216)$ of the respondents are willing to buy extra for a higher quality clothing product (question 5). The other answers' frequencies for the remaining four topic-related questions are displayed in Tables 2 and 3.

Table 1 | Convenience sample - frequency distribution of product quality consideration

\begin{tabular}{lccccc}
\hline & Never & Seldom & Sometimes & Very often & Always \\
\hline $\begin{array}{l}\text { product quality } \\
\text { clothing }\end{array}$ & $0(0 \%)$ & $8(3.3 \%)$ & $55(22.4 \%)$ & $133(54.1 \%)$ & $50(20.3 \%)$ \\
product quality & $1(0.4 \%)$ & $15(6.1 \%)$ & $73(29.7 \%)$ & $101(41.1 \%)$ & $56(22.8 \%)$ \\
\hline
\end{tabular}

Source: own research

Table 2 | Convenience sample - frequency distribution of parameters that people consider to label a clothing product as of quality (1 - the least important, 5 - the most important)

\begin{tabular}{lccccc}
\hline & $\mathbf{1}$ & $\mathbf{2}$ & $\mathbf{3}$ & $\mathbf{4}$ & $\mathbf{5}$ \\
\hline service life & $2(0.8 \%)$ & $19(7.7 \%)$ & $73(29.7 \%)$ & $82(33.3 \%)$ & $70(28.5 \%)$ \\
material & $8(3.3 \%)$ & $4(1.6 \%)$ & $33(13.4 \%)$ & $89(36.2 \%)$ & $112(45.5 \%)$ \\
price & $8(3.3 \%)$ & $19(7.7 \%)$ & $95(38.6 \%)$ & $59(24 \%)$ & $65(26.4 \%)$ \\
functionality & $6(2.4 \%)$ & $6(2.4 \%)$ & $43(17.5 \%)$ & $90(36.6 \%)$ & $101(41.1 \%)$ \\
appearance & $6(2.4 \%)$ & $22(8.9 \%)$ & $46(18.7 \%)$ & $78(31.7 \%)$ & $94(38.2 \%)$ \\
processing & $7(2.8 \%)$ & $7(2.8 \%)$ & $51(20.7 \%)$ & $92(37.4 \%)$ & $89(36.2 \%)$ \\
composition & $12(4.9 \%)$ & $29(11.8 \%)$ & $80(32.5 \%)$ & $66(26.8 \%)$ & $59(24 \%)$ \\
reputation & $9(3.7 \%)$ & $8(3.3 \%)$ & $62(25.2 \%)$ & $98(39.8 \%)$ & $69(28 \%)$ \\
region & $38(15.4 \%)$ & $57(23.2 \%)$ & $71(28.9 \%)$ & $40(16.3 \%)$ & $40(16.3 \%)$ \\
brand & $15(6.1 \%)$ & $48(19.5 \%)$ & $84(34.1 \%)$ & $62(25.2 \%)$ & $37(15 \%)$ \\
harmlessness & $13(5.3 \%)$ & $30(12.2 \%)$ & $63(25.6 \%)$ & $53(21.5 \%)$ & $87(35.4 \%)$ \\
\hline
\end{tabular}

Source: own research 
Table 3 | Convenience sample - frequency distribution of replies to questions 4, 6 and 7

\begin{tabular}{lllll}
\hline & $\begin{array}{c}\text { Strongly } \\
\text { disagree }\end{array}$ & $\begin{array}{c}\text { Rather } \\
\text { disagree }\end{array}$ & Rather agree & $\begin{array}{c}\text { Strongly } \\
\text { agree }\end{array}$ \\
\hline $\begin{array}{l}\text { To what extent do you agree } \\
\text { with the statement that } \\
\text { higher clothing prices } \\
\text { indicate higher quality? }\end{array}$ & $20(8.1 \%)$ & $91(37 \%)$ & $126(51.2 \%)$ & $9(3.7 \%)$ \\
$\begin{array}{l}\text { Do you agree with the } \\
\text { statement that the type of } \\
\text { store is an indicator that } \\
\text { more quality goods will } \\
\text { appear in it than low-quality } \\
\text { goods (e.g., fashion } \\
\text { boutique vs Asian store)? }\end{array}$ & & & \\
$\begin{array}{l}\text { Do you agree with the } \\
\text { statement that the store's } \\
\text { trade name is an indicator } \\
\text { that more quality goods } \\
\text { than low-quality goods will } \\
\text { appear in it (e.g. a Zara store } \\
\text { vs a store with an unknown } \\
\text { name)? }\end{array}$ & & & \\
\hline
\end{tabular}

Source: own research

We also analyzed the relationships within the convenience sample. First, we investigated relationships between parameters offered for answering within question 3 - by means of the correlation coefficient. The highest value of this coefficient was obtained for the pair "quality material" and "quality of processing" (0.653). All relationships together (using the correlation coefficient) are displayed in the dendrogram (Figure 1), which was obtained employing the complete linkage method.

Second, we investigated relationships between variables based on questions 1 to 7 , and the socio-demographic indicators based on questions 8 to 11. For sex, recoded age, and recoded permanent place of living (variables with two categories), the Mann-Whitney test was applied. For the completed level of education (a variable with three categories), the Kruskal-Wallis test was used. Moreover, the Pearson chi-square test of independence in a contingency table was applied for all investigated relationships. For question 5 (with answers "yes" and "no"), the chi-square test was only used.

In the next text, we discuss the relationships for the pairs of variables with significant dependences at the $5 \%$ significance level according to both types of statistical tests (both the tests for independent samples and the chi-square test). The description of the results is structured according to the individual demographic indicators. Concerning the recoded permanent place of living, no dependence was found. The following text describes the results for the other three indicators.

In the case of variable sex, we learned that the parameters corresponding price, region of production (e.g., a Czech product, not an Asian one), harmlessness to health related to question 3 are dependent on this demographic indicator. Women give the parameters more importance than men when determining whether a clothing product is of quality. The 
dependence on sex has also been found in question 7, where men tended to agree more than women with the statement that the store's trade name indicates that more quality goods than low-quality goods will appear in it. Cramer's V values ranged from 0.213 to 0.297 for these four pairs of variables (for the first three pairs, the dependences were significant even at the $1 \%$ significance level).

Figure 1 | Convenience sample - relationships among different parameters (variables) people consider when labelling a clothing product as of quality

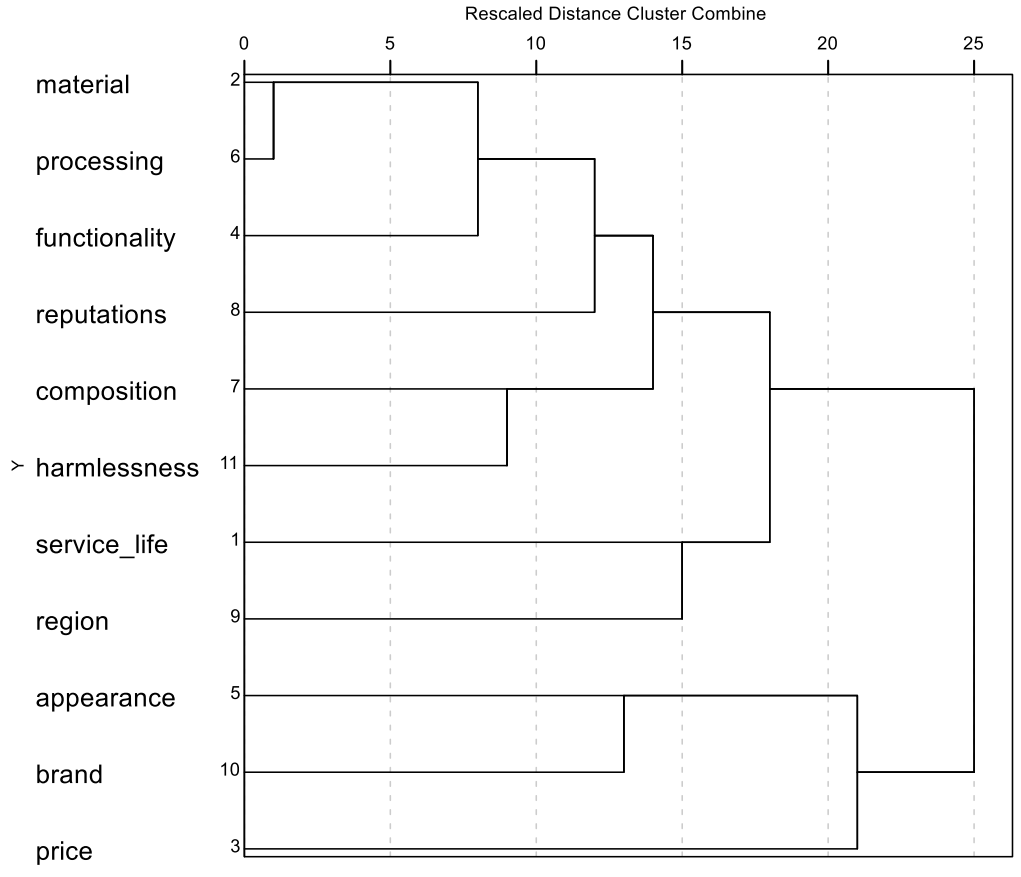

\section{Source: own research}

As concerns the recoded age intervals, older people tend to consider the quality of a product more frequently than younger people. The same is valid for considering the quality of a clothing product. Four parameters from question 3 are dependent on age. Quality material, quality of processing, good reputation, recommendations, reviews, own experience, and region of production are given more consideration by older people than by the younger at the moment of labelling a clothing product as of quality. Cramer's $V$ values ranged from 0.21 to 0.287 for these six cases (the dependencies were significant even at the $1 \%$ significance level with the exception of reputation).

In the case of the highest completed level of education, it was found out that there is a statistically significant dependence on the frequency with which people consider quality when buying a product. It seems that people with a higher level of completed education (secondary or university) could consider quality very often or always more frequently than people with only primary education level completed who appear to consider quality not that often. However, a look at the absolute values is not that convincing, so this result should be 
considered with a lot of caution. Moreover, the results show that people with a higher completed level of education are willing to pay extra for a higher quality of clothes, which is especially valid for people with a university degree.

In question 3, three parameters associated with perceived garment quality are dependent on the level of education. These are corresponding price, appearance, and region of production. The corresponding price parameter is given higher consideration mostly by people with a completed secondary level of education rather than with the completed basic or university level. As for the appearance parameter, people with the finished university level of education do not give the highest priority to the named aspects within this parameter as frequently as people with a lower level of completed education. Regarding the region of production, this parameter is given a higher level of consideration more frequently by people with completed secondary education and even more with completed university education. Cramer's $V$ values ranged from 0.182 to 0.279 for the pairs of variables with the completed level of education.

\subsection{Volunteer sample}

As a second step, we present results from volunteer sampling. This sampling was carried out with the help of a specialized website "vyplnto.cz". In the period between 3rd to 21st September 2020, we collected 120 answers (52 men and 68 women). Looking at the respective data set we downloaded, we again have not detected any suspicious ways of answering.

All but one respondent replied they consider quality to some extent when buying a product, and two persons stated never considering the quality of a clothing product when buying it (see Table 4). The volunteer sample results also reveal that $82,5 \%$ (99) of the respondents are willing to buy extra for a higher quality clothing product (question 5). The other answers' frequencies for the remaining four topic-related questions are displayed in Tables 5 and 6.

Table 4 | Volunteer sample - frequency distribution of product quality consideration

\begin{tabular}{lccccc}
\hline & $\mathbf{1}$ & $\mathbf{2}$ & $\mathbf{3}$ & $\mathbf{4}$ & $\mathbf{5}$ \\
\hline $\begin{array}{l}\text { product quality } \\
\text { clothing }\end{array}$ & $1(0.83 \%)$ & $1(0.83 \%)$ & $18(15 \%)$ & $70(25 \%)$ & $30(58.33 \%)$ \\
product quality & $2(1.67 \%)$ & $12(10 \%)$ & $27(22.5 \%)$ & $55(45.83 \%)$ & $24(20 \%)$ \\
\hline
\end{tabular}

Source: own research 
Table 5 | Volunteer sample - frequency distribution of parameters that people consider to label a clothing product as of quality ( 1 - the least important, 5 - the most important)

\begin{tabular}{lccccc}
\hline & $\mathbf{1}$ & $\mathbf{2}$ & $\mathbf{3}$ & $\mathbf{4}$ & $\mathbf{5}$ \\
\hline service life & $8(6.7 \%)$ & $8(6.7 \%)$ & $5(4.2 \%)$ & $48(40 \%)$ & $51(42.5 \%)$ \\
material & $8(6.7 \%)$ & $4(3.3 \%)$ & $8(6.7 \%)$ & $37(30.8 \%)$ & $63(52.5 \%)$ \\
price & $9(7.5 \%)$ & $12(10 \%)$ & $44(36.7 \%)$ & $29(24.2 \%)$ & $26(21.7 \%)$ \\
functionality & $7(5.8 \%)$ & $5(4.2 \%)$ & $16(13.3 \%)$ & $39(32.5 \%)$ & $53(44.2 \%)$ \\
appearance & $18(15 \%)$ & $24(20 \%)$ & $27(22.5 \%)$ & $25(20.8 \%)$ & $26(21.7 \%)$ \\
processing & $7(5.8 \%)$ & $3(2.5 \%)$ & $15(12.5 \%)$ & $39(32.5 \%)$ & $56(46.7 \%)$ \\
composition & $13(10.8 \%)$ & $4(3.3 \%)$ & $29(24.2 \%)$ & $36(30 \%)$ & $38(31.7 \%)$ \\
reputation & $6(5 \%)$ & $11(9.2 \%)$ & $32(26.7 \%)$ & $36(30 \%)$ & $35(29.2 \%)$ \\
region & $21(17.5 \%)$ & $26(21.7 \%)$ & $31(25.8 \%)$ & $15(12.5 \%)$ & $14(11.7 \%)$ \\
brand & $34(28.3 \%)$ & $26(21.7 \%)$ & $31(25.8 \%)$ & $15(12.5 \%)$ & $14(11.7 \%)$ \\
harmlessness & $14(11.7 \%)$ & $18(15 \%)$ & $17(14.2 \%)$ & $29(24.2 \%)$ & $42(35 \%)$ \\
\hline
\end{tabular}

Source: own research

Table 6 | Volunteer sample - frequency distribution of replies to questions 4, 6 and 7

\begin{tabular}{lllll}
\hline & $\begin{array}{c}\text { Strongly } \\
\text { disagree }\end{array}$ & $\begin{array}{c}\text { Rather } \\
\text { disagree }\end{array}$ & Rather agree & $\begin{array}{c}\text { Strongly } \\
\text { agree }\end{array}$ \\
\hline $\begin{array}{l}\text { To what extent do you agree } \\
\text { with the statement that }\end{array}$ & $21(17.5 \%)$ & $50(41.67 \%)$ & $37(30.83 \%)$ & $5(4.17 \%)$ \\
higher clothing prices \\
indicate higher quality?
\end{tabular}

Source: own research 
The analysis of the relationships within the volunteer sample showed us that again, the highest value of this coefficient was obtained for the pair "quality material" and "quality of processing" (0.745). All relationships together are displayed in the dendrogram (Figure 2).

Figure 2 | Volunteer sample - relationships among different parameters (variables) people consider when labelling a clothing product as of quality

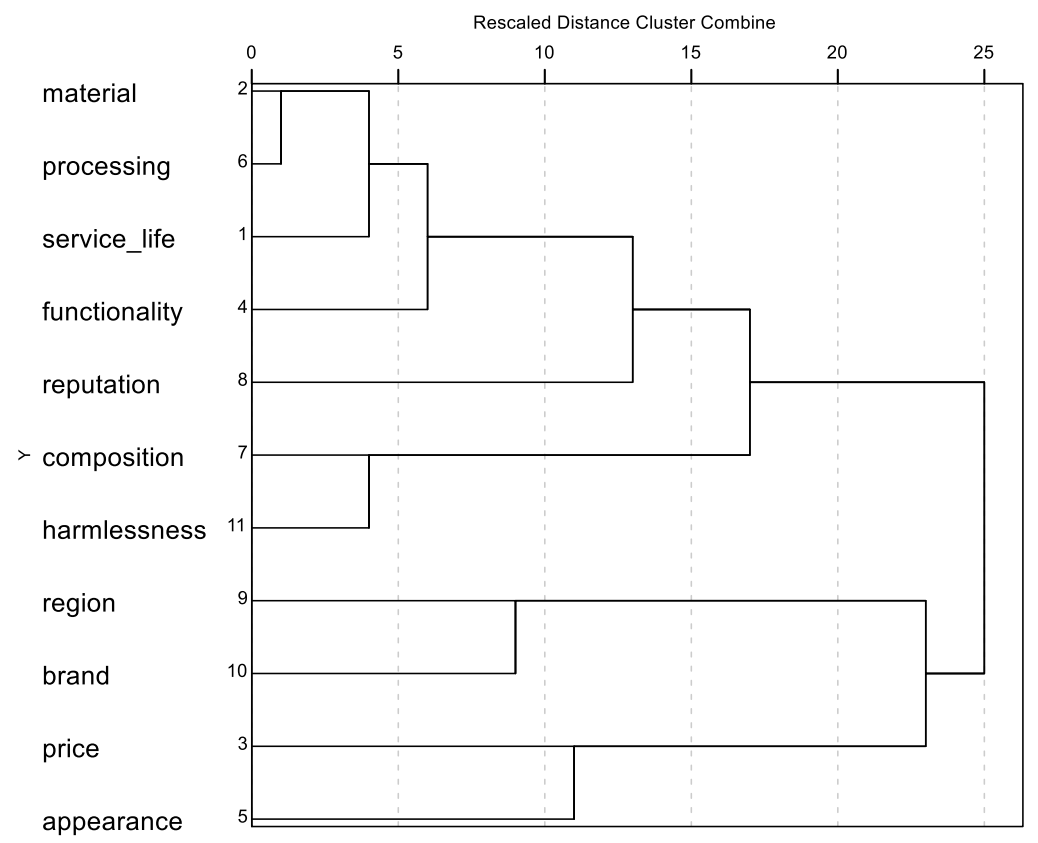

Source: own research

Regarding relationships between variables based on questions 1 to 7 , and the demographic indicators obtained from questions 8 to 11 , we found fewer statistically significant dependences than in the case of the convenience sample. This fact is, to some extent, influenced by a lower number of answers received.

The same tests were applied, i.e., the Mann-Whitney test (for sex, recoded age, and recoded permanent place of living), the Kruskal-Wallis test (for the completed level of education), and the chi-square test of independence in a contingency table (for all investigated relationships). For question 5 (with answers "yes" and "no"), the chi-square test was only used. In the variable place of living (recoded), we found one significant dependence, this for question 6 using the Mann-Whitney test only (P-value 0.04). Concerning gender, no dependence was found.

Now, we discuss the relationships for the pairs of variables with significant dependences at the $5 \%$ significance level according to both types of statistical tests (both the tests for independent samples and the chi-square test). 
Regarding the variable completed level of education, the Kruskal-Wallis test and the chisquare test found the dependence between education level and the frequency with which people consider product quality when buying a product. It again appears that people with a higher level of completed education could consider quality very often or always more frequently than people with only primary education level. Solely the Kruskal-Wallis test confirmed significant dependences between the level of education and the parameters quality material and quality of processing. People with university education and people with secondary education give these two parameters the highest consideration when determining a product as of quality more frequently than people with primary education only. Cramer's $\mathrm{V}$ values ranged from 0.223 to 0.264 for these three cases.

As concerns the recoded age intervals, older people from the volunteer sample tend to consider the quality of a product more frequently than younger people, but this was not proved for consideration of clothing products. Three parameters from question 3 are dependent on age: quality material, quality of processing, and good reputation, recommendations, reviews, own experience. People aged 26 years and older give these parameters the highest consideration when determining a quality product more frequently than people aged 25 or less.

For all mentioned relationships, statistical dependence was tested based on the MannWhitney test and the chi-square test. The dependence between the quality of processing and age was significant even at the $1 \%$ significance level, in the other cases at the $5 \%$ significance level. Cramer's $\vee$ values ranged from 0.29 to 0.41 for these four cases.

\subsection{Comparing two samples}

At this stage, we compare the two samples to determine whether there are common results. Based on cluster analysis, we found two groups of parameters included in question 3 in both samples. There are appearance, brand and price in one group in both samples. In the volunteer sample, the region is also included in this group. All other parameters are clustered into the second group. So, we can confirm our first scientific hypothesis that groups of parameters exist. Comparing the dendrograms in Figures 1 and 2 in detail, we can see that the relationships among variables are similar in some aspects. The highest correlation is for the pair material and processing in both samples $(0.653$ and 0.731$)$. The second correlated pair are composition and harmlessness (0.399 and 0.641).

Significance dependences resulting from nonparametric tests for independent samples (Mann-Whitney/Kruskal-Wallis) are indicated in Table 7. We found price, region, harmlessness, and question 7 depended on sex only on the basis of the convenience sample. So, we cannot confirm the second scientific hypothesis. However, we found that material, processing, and reputation depended on the age groups in both samples (in all the three cases and in both samples, people aged 26 and over give more priority to named parameters). The third hypothesis can be confirmed. We cannot confirm either the fourth or the fifth hypothesis concerning dependence on the completed level of education and the permanent place of living because we did not find any meritorious variable dependent on these explanatory demographic parameters in both samples simultaneously. In addition, we can mention that question 1 depends on both the age groups and the completed level of education in both samples. People aged 26 or over and people with secondary or university education consider the quality of products more often when purchasing them. For clothing 
products, the intensity of quality consideration does not seem to depend on any demographic parameter.

Nonetheless, we also tested whether there is a dependence on the type of sample (convenience sample vs volunteer sample). The results obtained by the Mann-Whitney test are shown in Table 7 (the last column). We found that differences between the two types of surveys are only for such variables for which no dependence on demographic indicators was found in individual samples (except the pair question 7 and sex in sample 1).

Table 7 | Significance dependences according to nonparametric tests for independent samples (Mann-Whitney / Kruskal-Wallis) or according to the Pearson chi-squared test (for question 5)

\begin{tabular}{|c|c|c|c|c|c|c|}
\hline \multirow{2}{*}{$\begin{array}{l}\text { Explanatory } \\
\text { variable } \\
\text { Target var. }\end{array}$} & \multicolumn{3}{|c|}{ Convenience sample } & \multicolumn{2}{|c|}{ Volunteer sample } & \multirow{2}{*}{$\begin{array}{l}\text { Type of } \\
\text { survey }\end{array}$} \\
\hline & $\operatorname{sex}$ & age & education & age & education & \\
\hline question 1 & & yes & yes & yes & yes & \\
\hline question 2 & & yes & & & & \\
\hline service life & & & & & & yes \\
\hline material & & yes & & yes & yes & \\
\hline price & yes & & yes & & & \\
\hline functionality & & & & & & \\
\hline appearance & & & yes & & & yes \\
\hline processing & & yes & & yes & yes & \\
\hline composition & & & yes & & & \\
\hline reputation & & yes & & yes & & \\
\hline region & yes & yes & yes & & & \\
\hline brand & & & & & & yes \\
\hline harmlessness & yes & & & & & \\
\hline question 4 & & & & & & yes \\
\hline question 5 & & & yes & & & \\
\hline question 6 & & & & & & yes \\
\hline question 7 & yes & & & & & yes \\
\hline
\end{tabular}

Source: own research

\section{Discussion}

The results presented above are hardly comparable to past research. The first reason is that, in general, perceived garment quality has not been a frequent centre of the researcher's interest. The second reason is that our questionnaire has been primarily designed to narrow 
the even greater significant research gap in understanding whether (and if, then how) the major different socio-demographic groups perceive the garment quality. It is, however, possible to associate some of our findings with the existing research.

First and foremost, sex has not resulted in being a decisive socio-demographic variable in the assessment of perceived garment quality. This is a clear discrepancy with the existing research (Gitimu et al., 2013, Freire Castelo \& de Oliveira Cabral, 2018, Lee \& Workman, 2021). One can object that this is because our volunteer sample (120 respondents) was much smaller than the convenience sample (246 respondents). However, sex was not statistically significant for most of the assessed parameters even in the convenience sample.

On the contrary, age has resulted in being a significant socio-demographic indicator for some factors characterizing quality (material, processing, and reputation). This is in accordance with the study of Popa and Pelau (2016). For the completed level of education and permanent place of living, we did not find any statistical significance appearing simultaneously in both samples on the meritorious questions asked. There is no relevant literature linking the perceived quality of clothing with these two indicators. Therefore, no comparison can be carried out. In the following paragraphs, associations worth commenting on are presented.

Gerstner (1985) study's findings indicated that quality-price relations depend on the product. Although the products examined by Gerstner included only one clothing item (trench coat), it is worth mentioning that he concluded that for many products, the relation between quality and price is weak and that for many products, higher prices appear to be poor signals of higher quality.

Narrow-oriented research of Verma and Gupta (2004) set in the Indian environment assessed three different products, one of them being a T-Shirt. The scientists determined that their sample of 175 respondents perceived that the lower the T-shirt's price, the more inferior the quality would be. However, the respondents were a bit sceptical about the "high price superior quality" relationship.

Whereas within our convenience sample, the share of disagreeing answers to question 4 (45.1\%) was almost equal to the percentage of affirmative answers (54.9\%), respondents from the volunteer sample were mostly negative in their responses $(59.17 \%$ vs $35 \%$, the rest, $5.83 \%$, belongs to the "I do not know" option). These numbers reveal that a significant share of our respondents is sceptical when considering the rising price-growing quality relation. Given the great disparity of consumers' perception, the issue of quality-price relation for clothing products should be subject to further analysis.

Our two samples show that over $80 \%$ of respondents claim to be willing to pay extra for a higher-quality product. Results from question 3 reveal which parameter is the most important for considering a clothing product as of quality. For both samples, quality material is the most relevant. The parameters quality of processing, meeting functional expectations, long service life, and good reputation, ... follow. Conversely, both samples' answers indicate that brand and region of production are the least important when labelling a clothing product as of quality. Thus, we can claim that clothing products' intrinsic characteristics can be a more reliable indicator of quality for people buying a clothing product than extrinsic traits. At the same time, our statement would support Olson and Jacoby's (1972) assumption that intrinsic cues have a more powerful effect on quality judgments than extrinsic cues. Other studies would be in accordance with this assumption, such as that of Davis (1985). She, carrying out 
small research with a sample of 78 women examining and rating the quality of skirts, learned that intrinsic cues such as physical quality might be more important than extrinsic cues. We would also support Olson and Jacoby's (1972) assumption that price (an extrinsic cue), although being an important factor to consider in a purchase decision, is generally not perceived to be as good of an indicator of quality as are certain intrinsic cues. Therefore, producers and marketers of clothing products could consider in their decision-making these differences in consumer perception more often than what has been considered thus far.

Grewal and Baker (1994) asserted that a store's environment's characteristics influence the inferences that customers make about the store's merchandise. Our two samples have mostly supported the statement expressed in question 6 that the type of store indicates that more quality goods will appear in it than low-quality goods (83.3\% of affirmative answers in the convenience sample and $61.67 \%$ of affirmative responses in the volunteer sample; in the latter sample, $10 \%$ could not decide). We would thus agree with Morganosky's (1990) recommendation that clothing manufacturers need to be cognizant of the potential harm that can occur to their quality image because of association with certain store types.

Steenkamp (1989), performing a meta-analysis of previous studies, concluded that store name, among other cues, influences quality perceptions. Still, he added it does not imply a significant effect on perceived quality for all products and in all situations. In our research, stores' trade names do not seem to be such an important indicator of whether more quality goods will appear in the stores than low-quality goods $(44.3 \%$ of negative answers from the convenience sample and $51.67 \%$ of negative responses from the volunteer sample).

\subsection{Limitations}

We find three main limitations of our paper. First, we focused on one country only. However, we preferred to investigate the selected issues deeply rather than being geographically extended, thus to opt for two independent samples and to assess and comparing them thoroughly. We believe that deploying a new questionnaire simultaneously in various countries would result in a lengthy and drawn-out paper risking that people from other countries would understand a new questionnaire differently. Also, the question of which countries should be preferred for comparison would need to be answered along with how to justify their selection adequately.

The second main limitation consists of the factors which we have decided to link with the perceived quality. Nonetheless, as it is visible from the lines above, it was preferred to "make some balance" using a model questionnaire from an institution and modifying it to our topic's needs. Some of the factors were already assessed in other research; some were not.

The third main limitation is the number of respondents in both samples. In a smaller sample of respondents like ours, we might not find all the dependencies. We, therefore, cannot exclude that other dependencies can exist. Though, having two samples gave us a higher level of validity for our hypotheses testing, meaning that one sample served as a confirmation tool for the other sample and v.v.

\subsection{Implications and future directions}

In spite of some limitations, this paper contributes both to theory and practice. Regarding theory, some authors (e.g., Gitimu et al., 2013; Salerno-Kochan \& Turek, 2021) called for a 
better assessment of demographic indicators vis-à-vis the different aspects associated with perceived garment quality. This paper responds especially to these calls, which are not a surprise because, as pointed out in the literature review, researchers have tended to be very restrictive either in the scales or in the respondents' profile applied for their research on perceived garment quality or even in both senses. This paper thus comes with an indiscriminative approach towards the potential respondents while simultaneously offering a large number of both parameters and some other meritorious questions.

Regarding practical implications, businesses from the Czech Republic or other countries from the same region receive a clear indication on which of the assessed aspects are currently of higher or lower importance for Czech consumers. Our research's results show that some intrinsic parameters, especially functionality and used materials, are of higher importance for Czech clothing users than most of the assessed extrinsic parameters, although some extrinsic cues, especially appearance and price, may be as influential for some segments of consumers.

Designing a questionnaire from scratch is always a challenge for any researcher, but all the mentioned findings, as well as limitations, give enormous space for further investigation. It should be remembered that consumers' choices are unstable and unpredictable, and clothing industries worldwide face stiff competition (Nayak \& Padhye, 2015). Very little is still known about consumers' perception of clothing quality, so we believe that our paper may help businesses from the clothing sector and related industries obtain a better understanding of how quality and associated aspects are currently perceived among different categories of people. Due to the fact that our paper is pioneering and limited to one country only, we suggest that further research is carried out in other countries to learn whether certain types of consumers behave similarly or differently there. Additionally, this paper may not only serve as a sound theoretical basis for conducting surveys in other countries but also for investigations into product types other than clothing.

\section{Conclusion}

This paper offers a novel insight into garment quality perception. After studying previous research, we meticulously analyzed the perception of garment quality on two independent samples of Czech consumers. Not only did we focus on different parameters by which people determine a clothing product as of quality, but we also examined how frequently they consider quality when either buying any product or when buying a clothing product. Moreover, we investigated relationships between quality and other aspects: price level, willingness to pay more for a higher-quality clothing product, type of store, and store's trade name.

We compared the two samples to learn whether there are some common tendencies in perception. First, our comparison demonstrates that people aged 26 and over give more priority to quality material, quality of processing, and positive feedback or experience (i.e., good reputation, ...) with the clothing product to determine that the latter is of quality than people aged 25 or less.

Second, the completed level of education and age play an essential role in the frequency with which people consider quality when buying a product. People aged 26 and over and people with a higher education level than primary tend to assess the quality of the purchased product 
more frequently. However, the dependences of the frequency of quality consideration on achieved education and age have not particularly been confirmed for clothing products.

Third, employing the correlation coefficient, we discovered that people expressing their priority in the parameter quality material tended to answer similarly in the parameter quality of processing in both samples we had.

Fourth, it was also found that an important number of respondents from our samples did not accept the statement that growing price signals higher quality. Nonetheless, a large majority of all the respondents would be willing to pay more for a higher-quality product. We also found out that Czech respondents primarily associated quality with quality materials.

Lastly, we learned that the store type has mostly been seen as an indicator of whether there will be more quality clothes than low-quality clothes. Contrarily, our respondents were considerably more negative when deciding whether the stores' trade names could indicate the same.

\section{Acknowledgement}

This article was prepared with the institutional support of the Faculty of International Relations and the Faculty of Informatics and Statistics of the Prague University of Economics and Business.

\section{References}

Aakko, M., \& Niinimäki, K. (2021). Quality matters: reviewing the connections between perceived quality and clothing use time. Journal of Fashion Marketing and Management: An International Journal (in print).

Bhardwaj, V., \& Fairhurst, A. (2010). Fast fashion: response to changes in the fashion industry. The International Review of Retail, Distribution and Consumer Research, 20(1), 165-173.

Chowdhury, M., Paul, H., \& Das, A. (2007). The impact of top management commitment on total quality management practice: An exploratory study in the Thai garment industry. Global Journal of Flexible Systems Management, 8(1-2), 17-29.

Coelho, D. C. (2016). Older Female Consumers' Quality Perception of Clothing During Pre-and PostPurchase Decisionmaking (Doctoral dissertation, North-West University (South Africa), Potchefstroom Campus).

Connor-Crabb, A., \& Rigby, E. D. (2019). Garment quality and sustainability: A user-based approach. Fashion Practice, 11(3), 346-374.

Davis, L. L. (1985). Effects of physical quality and brand labeling on perceptions of clothing quality. Perceptual and Motor Skills, 61(2), 671-677.

Davis, L. L. (1987). Consumer use of label information in ratings of clothing quality and clothing fashionability. Clothing and Textiles Research Journal, 6(1), 8-14.

D'Astous, A., \& Saint-Louis, O. (2005). National versus store brand effects on consumer evaluation of a garment. Journal of Fashion Marketing and Management: An International Journal, 9(3), 306317.

Du Preez, M., Dreyer, H., Botha, E., van der Colff, N., Coelho, D. C., \& Pretorius, M. (2018). Older female consumers' clothing quality perception: expectations and performance. Journal of Consumer 
Sciences, $46 . \quad$ Retrieved 29th August, 2020, from https://www.ajol.info/index.php/jfecs/article/view/180030/169370

Erdoğmuş, İ., \& Büdeyri-Turan, I. (2012). The role of personality congruence, perceived quality and prestige on ready-to-wear brand loyalty. Journal of Fashion Marketing and Management: An International Journal, 16(4), 399-417.

Freire Castelo, J. S., \& de Oliveira Cabral, J. E. (2018). Consumers in a social network: the perception of clothing quality per gender. Revista Brasileira de Gestão de Negócios, 20(1), 22-36.

Gerstner, E. (1985). Do higher prices signal higher quality? Journal of Marketing Research, 22(2), 209215.

Gitimu, P. N., Workman, J., \& Robinson, J. R. (2013). Garment quality evaluation: Influence of fashion leadership, fashion involvement, and gender. International Journal of Fashion Design, Technology and Education, 6(3), 173-180.

Grewal, D., \& Baker, J. (1994). Do retail store environmental factors affect consumers' price acceptability? An empirical examination. International Journal of Research in Marketing, 11(2), 107-115.

Jacobson, R., \& Aaker, D. A. (1987). The strategic role of product quality. Journal of Marketing, 51(4), $31-44$.

Jung, S., \& Jin, B. (2014). A theoretical investigation of slow fashion: sustainable future of the apparel industry. International Journal of Consumer Studies, 38(5), 510-519.

Kaplan, S., \& Okur, A. (2008). The meaning and importance of clothing comfort: A case study for Turkey. Journal of Sensory Studies, 23(5), 688-706.

Kaynak, E., Kucukemiroglu, O., \& Hyder, A. S. (2000). Consumers' country-of-origin (COO) perceptions of imported products in a homogenous less-developed country. European Journal of Marketing, 34(9/10), 1221-1241.

Lane, C., \& Probert, J. (2004). Between the global and the local: a comparison of the German and UK clothing industry. Competition \& Change, 8(3), 243-266.

Lee, S., Johnson, S., \& He, X. (2009). Brand origin or product origin? The effects of country of origin fit on brand evaluation. In A. L. McGill, \& S. Shavitt (Eds.), Advances in Consumer Research, Volume 36, (pp. 1013-1014).

Lee, S. H., \& Workman, J. E. (2021). Trendsetting and gender matter: Brand loyalty, perceived quality, and word-of-mouth. Journal of Global Fashion Marketing, 12(1), 16-31.

Mitra, A. (2016). Fundamentals of Quality Control and Improvement. John Wiley \& Sons.

Milašius, R., \& Mikučioniené, D. (2014). Comparative analysis of textile and clothing industry in the EU and Turkey. Fibres \& Textiles in Eastern Europe, 3(105), 8-16.

Miller, T. O. (1992). A customer's definition of quality. Journal of Business Strategy, 13(1), 4-7.

Morganosky, M. A. (1990). Store and brand type influences on the perception of apparel quality: A congruity theory approach. Clothing and Textiles Research Journal, 9(1), 45-49.

Nayak, R., \& Padhye, R. (2015). Introduction: the apparel industry. In Nayak, R., \& Padhye (Eds.), Garment Manufacturing Technology (pp. 1-17). Woodhead Publishing.

Olson, J. C., \& Jacoby, J. (1972). Cue utilization in the quality perception process. In M. Venkatesan (Ed.), SV - Proceedings of the Third Annual Conference of the Association for Consumer Research (pp. 167-179). Chicago: Association for Consumer Research. 
Park, H. R. (2015). The Consumers' evaluative criteria of quality on the organic clothes and their purchase intention. Journal of the Korea Academia-Industrial cooperation Society, 16(11), 80018011.

Popa, A., \& Pelau, C. (2016). Differences in the clothing brand perception depending on generation/Diferente în perceptia brandurilor de îmbracaminte în functie de generatie. Industria Textila, 67(4), 260.

Pujara, T., \& Chaurasia, S. (2010). Understanding the young consumers' perception of clothing quality. Quest-Journal of Management \& Research, 1(2), 53-61.

Rahman, O., Fung, B. C., Chen, Z., \& Gao, X. (2017). A cross-national study of apparel consumer preferences and the role of product-evaluative cues. Asia Pacific Journal of Marketing and Logistics, 29(4), 796-812.

Saleem, A., Ghafar, A., Ibrahim, M., Yousuf, M., \& Ahmed, N. (2015). Product perceived quality and purchase intention with consumer satisfaction. Global Journal of Management and Business Research, 15(1), 20-28.

Salerno-Kochan, R., \& Turek, P. (2021). Consumer perception vs sensory assessment of the quality of clothes of selected brands available on the Polish market. Journal of Fashion Marketing and Management: An International Journal (in print).

Steele, V., \& Major, J. S. (2015). Fashion industry. Encyclopedia Britannica. Retrieved 3rd September, 2020, from https://www.britannica.com/art/fashion-industry

Steenkamp, J. B. E. M. (1989). Product quality : an investigation into the concept and how it is perceived by consumers. Steenkamp. Retrieved 2nd September, 2020, from https://edepot.wur.nl/51607

Stengg, W. (2001). The textile and clothing industry in the EU. Enterprise papers, (2). Retrieved 27th August, 2020, from https://edz.bib.uni-mannheim.de/www-edz/pdf/entpap/ep-02-2001.pdf

Swinker, M. E., \& Hines, J. D. (2006). Understanding consumers' perception of clothing quality: A multidimensional approach. International Journal of Consumer Studies, 30(2), 218-223.

The World Bank (2020). Textiles and Clothing. Retrieved 2nd September, 2020, from https://data.worldbank.org/indicator/NV.MNF.TXTL.ZS.UN

Thomassey, S. (2010). Sales forecasts in clothing industry: The key success factor of the supply chain management. International Journal of Production Economics, 128(2), 470-483.

Tsiotsou, R. (2005). Perceived quality levels and their relation to involvement, satisfaction, and purchase intentions. Marketing Bulletin, 16(4), 1-10.

Tyagi, S. K., Cai, X., \& Yang, K. (2015). A literature survey and future directions for product development: A focus on conceptual design stage. Journal of Cost Analysis and Parametrics, 8(2), 108-125.

Verma, D. P. S., \& Gupta, S. S. (2004). Does higher price signal better quality? Vikalpa, 29(2), 67-78.

Yürek, M. A., Natsuda, K., Akkemik, K. A., \& Yağmur, M. H. (2019). The textile and clothing industrialization cycle. Marmara University Journal of Economic \& Administrative Sciences, 41(1), 256-277.

The research article passed the review process. | Received: May 11, 2021; Revised: August 27, 2021; Accepted: September 18, 2021; Pre-published online: December 22, 2021; Published in the regular issue: May 19, 2022. 